\title{
El ejercicio subordinado de la abogacía: límites e implicancias de las cargas deontológicas so- bre la relación laboral del abogado
}

\author{
MARIELENA HOUGHTON SOTO*
}

\begin{abstract}
SUMARIO.- I. INTRODUCCIÓN.- II. FUNDAMENTO DE LA EXISTENCIA DE UNA RELACIÓN LABORAL.- III. PODER DE DIRECCIÓN VS. OBLIGACIONES DEONTOLÓGICAS: VINCULACIÓN DE AMBAS ESFERAS DEL ABOGADO-TRABAJADOR.- IV. BUSCANDO SOLUCIONES: EL DERECHO DE RESISTENCIA O JUS RESISTENTIAE.- V. CONCLUSIONES.
\end{abstract}

\section{INTRODUCCIÓN}

Los abogados, ciertamente, pueden desempeñarse bajo el marco de contrato de trabajo, con lo cual encontramos que existe un intercambio de derechos y deberes típicos de una relación laboral que se sobreponen a los derechos y deberes de todo abogado como tal en el ámbito de la ética y responsabilidad profesional, entendida esta como una responsabilidad disciplinaria y no como una civil, al margen de su condición de trabajador dependiente.

De esta manera, el marco de la relación laboral faculta a la organización, como empleador, con el poder de dirección para otorgarle las atribuciones de dirigir, fiscalizar y sancionar al abogado que labora bajo su subordinación, y dotan también de una presunción de legitimidad a las órdenes que emita. Asimismo, el Derecho laboral otorga al abogado garantías y medios de tutela contra las órdenes del empleador que sean lesivas a su integridad física y moral y, en general, que vulneren derechos fundamentales, lo que es conocido como «derecho de resistencia». Sin embargo, el abogado, por el solo hecho de ser abogado, ya cuenta con una serie de mecanismos orientados a proteger su integridad y su conciencia bajo el amparo de las disposiciones de la ética y la responsabilidad profesional del abogado, contenidas actualmente en el Código de Ética del Colegio de Abogados del Perú y que han sido recogidas en el Proyecto de Código de Responsabilidad Profesional del Abogado. ${ }^{1}$

\footnotetext{
* BachillerenDerechoporlaPontificiaUniversidadCatólicadelPerú, asistentededocenciadelcursodeÉtica yResponsabilidadProfesional del Abogadoen laFacultad deDerechodelaPontificiaUniversidadCatólica del Perú y miembro de Ernst \& Young. El presente artículo es parte de la tesis que la autora desarrolla para obtener el título de abogado. Agradece el incansable apoyo y la motivación de Beatriz Boza.

1 El Proyecto de Código de Responsabilidad Profesional del Profesional en Derecho es una iniciativa de la PontificiaUniversidadCatólicadelPerúlideradaporeldoctorWalterAlbán, DecanodelaFacultaddeDerecho de la PUCP, bajo la secretaría de la doctora Beatriz Boza. La Exposición de Motivos ha sido formalizada mediante la publicación de la Asociación Civil Thēmis. Ver: Boza, Beatriz y Chocano, Christian. Exposición deMotivos delProyectodeCódigodeÉticay ResponsabilidaddelProfesionalen Derecho. Themis, Primera edición, octubre 2008.
} 
En este escenario, nos preguntamos si el derecho del abogado a aceptar libremente un encargo o no, o la facultad que tiene para renunciar a un patrocinio por causas que ahondaremos en la investigación, así como restringir el secreto profesional solo hacia su cliente, con lo que se excluiría la injerencia del empleador, entre otros supuestos, contraviene con su obligación como trabajador de cumplir cabalmente con la prestación pactada. Asimismo, analizaremos si los deberes y derechos profesionales del abogado dotan de contenido al derecho de resistencia del trabajador y, si es así, de qué manera lo hacen; cuáles son los límites del derecho de resistencia del abogado subordinado y si sus deberes y derechos profesionales representan un límite al poder de dirección del empleador o, si este medra, desde el punto de vista de la responsabilidad profesional, la libertad del abogado a desarrollar su prestación. Echemos una mirada.

\section{FUndAMENTO DE LA EXISTENCIA DE UNA RELACIÓN LABORAL}

Si bien la percepción de la realidad en el mercado de los servicios legales nos denota el ejercicio autónomo de la abogacía, no es menos cierto que los abogados pueden desempeñarse perfectamente bajo el amparo del Derecho laboral, con lo cual tenemos abogados que ejercen de manera independiente, asociativa o, finalmente, subordinada.

Sobre el ejercicio subordinado de la profesión, si el abogado cumple con los tres requisitos de un contrato de trabajo - (i) prestación personalísima, (ii) remuneración y (iii) subordinación-, el desarrollo de sus servicios se encuadrará necesariamente dentro de una relación laboral. ${ }^{2}$

Analizando dichos elementos en el caso de los abogados, la prestación personal, entendida como el objeto del contrato de trabajo, es el motivo para lo cual se contrata al abogado: asesoría, préstamo de diversos servicios como asociado en un estudio de abogados, manejo de los asuntos legales de una empresa, etcétera, los cuales solo pueden ser desarrollados por el abogado en particular. Por su parte, el elemento remunerativo no es equiparable, en principio, a los honorarios que el abogado cobra por sus servicios, ya que el abogado puede pactar un honorario sobre la base de una tarifa preestablecida, como miembro integrante de una organización, y a la par recibir efectivamente una retribución económica fija — esta última no pactada con el cliente, sino con su empleador-, la cual sí calzaría con la noción de remuneración propiamente dicha.

Finalmente, la subordinación es «un vínculo jurídico entre el deudor y el acreedor del trabajo, en virtud del cual el primero le ofrece su actividad al segundo y le confiere el poder de conducirla». ${ }^{3}$ De lo dicho 
se desprende que sujeción y dirección son dos aspectos centrales del concepto, ${ }^{4}$ ya que el abogado-trabajador queda sometido al empleador y a las directrices que este imparta para el mejor desarrollo de la prestación.

Sin embargo, Carlos Blancas ${ }^{5}$ hace una precisión sobre esta concepción generalizada de subordinación, al basarse en la evolución de las formas productivas y la organización empresarial, para concluir que el elemento determinante en el concepto de subordinación es el hecho de que el abogado-trabajador pone a disposición del empleador su fuerza de trabajo, con independencia del grado de subordinación técnica a la que esté sujeto. Sobre el tema, el autor además señala que se ha ampliado el concepto de subordinación y se ha incluido, para quienes prestan labores intelectuales o profesionales, un elevado grado de independencia técnica.

En la práctica peruana, podemos observar que la contratación laboral de los abogados es característica de las empresas, mas no de las firmas de abogados, la mayoría formados bajo un modelo asociativo. Sin embargo, como acabamos de analizar, es válida - y, desde nuestro particular punto de vista, necesaria- la existencia de un contrato de trabajo con los abogados en cualquier escenario, siempre y cuando se cumpla con los requisitos antes mencionados.

Entonces, partiendo de las prestaciones subordinadas de servicios del abogado como premisa general, nos preguntamos cuáles son las implicancias que surgen en las distintas esferas de este especial trabajador que ingresa a una relación laboral con una carga de derechos y deberes ya predeterminados por normas y principios distintos de los laborales, pero que mucho tienen que ver con la ética del trabajador.

Sobre la ética en el contrato de trabajo, Alonso García ${ }^{6}$ presenta un fragmento interesante para explicar que el contrato de trabajo involucra un complejo de relaciones, no solo jurídicas, sino también económicas y morales. Específicamente sobre lo último, ha señalado que:

El contenido del contrato de trabajo puede ser desglosado en tres aspectos diferentes: 1) patrimonial, referido a la valoración económica de las prestaciones del trabajador y del empresario, y por ende a las prestaciones mismas; 2) ético, que comprende el modo en que estas prestaciones han de hacerse efectivas; y 3) el jurídico, que se refiere a la titularidad de los resultados del trabajo o servicios realizados (la cursiva es nuestra).

De lo dicho se desprende que los ámbitos de la ética, la moral, la responsabilidad profesional y, en general, la deontología no son ajenos al contrato de trabajo, con lo cual ya tenemos una primera aproximación.

EL EJERCICIO SUBORDINADO DE LA ABOGACÍA: LÍMITES E IMPLICANCIAS DE LAS CARGAS DEONTOLÓGICAS SOBRE LA RELACIÓN LABORAL DEL ABOGADO 


\section{III.PODER DE DIRECCIÓN VS. OBLIGACIONES DEONTOLÓGICAS: VINCULACIÓN DE AMBAS ESFERAS DELABOGADO-TRABAJADOR}

Como señalamos en el punto II, el elemento de la subordinación es esencial para configurar la existencia de una relación laboral, lo cual implica, con ciertos límites, que el empleador tenga atribuciones como dirigir, fiscalizar y sancionar al abogado-trabajador, lo que es llamado «poder de dirección».

Hemos adelantado que el poder de dirección, si bien es ciertamente discrecional, no es absoluto ni arbitrario, sino que más bien presenta límites en su ejercicio. Asimismo, todas estas atribuciones están interrelacionadas y agrupadas dentro del concepto de poder de dirección; lo dotan de contenido y se establecen como característica esencial del empleador, siendo el fundamento de esta facultad la libertad de empresa, ${ }^{7}$ que no solo abarca crearla y establecerla, sino, consecuentemente, organizarla y dirigirla. De lo dicho se desprende, además, que un empleador impedido de decidir cómo desarrollar la prestación en su totalidad pues simplemente no es un empleador.

En relación con el trabajador, el poder de dirección surge como una consecuencia inmediata, en favor del empleador, de la suscripción del contrato de trabajo entre ambos. Por tanto, el empleador es el titular del poder de dirección y sus directrices están dotadas de una presunción de legitimidad.

Sobre esta línea, Javier Neves ${ }^{8}$ señala como un primer límite al poder de dirección del empleador, el servicio específico y concreto por el cual se ha contratado al trabajador, sin que el empleador pueda variar la labor convenida inicialmente con el anterior, salvo que se trate de labores contenidas dentro de la misma categoría pactada al inicio de la relación laboral.

$\mathrm{Al}$ respecto, en el caso concreto del abogado-trabajador, somos de la opinión de que el empleador tiene un margen más amplio para modificar la prestación, ya que esta, por lo general, es pactada de manera más abierta - como ocurre, por ejemplo, con la asesoría legal, que implica absolver consultas, redactar contratos, verificar procedimientos, entre otras labores-. Sobre esta línea, si el empleador ordena al abogadotrabajador pasar de una asesoría en tributación a la representación en un procedimiento penal, estaríamos dentro del ejercicio legítimo del poder de dirección del empleador, aunque el empleador debe velar por que el abogado-trabajador sea lo suficientemente competente para asumir el nuevo encargo y, sobre todo, cuidar de no dejar desprotegido a su cliente en caso de un eventual retiro del patrocinio. Lo contrario a lo expuesto implicaría, en nuestra opinión, cambiar al abogado-trabajador del puesto de asistente legal hacia el de ayudante de fotocopias 
$\mathrm{u}$ ordenar al especialista en Derecho de familia que atienda consultas de Derecho aduanero, a pesar de no estar capacitado para ello.

El segundo límite ${ }^{9}$ que la doctrina mayoritaria plantea está determinado por la existencia de derechos fundamentales ${ }^{10}$ de los trabajadores que son de observancia obligatoria para el empleador, ya que en el marco de una relación laboral no solo interactúan los derechos netamente laborales, sino también subsisten - y se incorporan a ella— los derechos fundamentales, los cuales son llamados, en Derecho laboral, «derechos inespecíficos».

Al respecto, Jorge Toyama comenta la sentencia recaída en el expediente 3935-99-I.D. (S) ${ }^{11}$ y afirma que «por los derechos inespecíficos se limita el poder de dirección del empleador dado que ya no podría dictar órdenes que atenten contra los derechos no laborales de los trabajadores y éstos podrían cuestionarla válidamente».

En este nivel de nuestro análisis, tenemos un abogado-trabajador que presta un servicio personal y remunerado, en situación de dependencia, para un empleador quien, en virtud de un contrato de trabajo, puede ejercer su poder de dirección para el mejor desarrollo de la prestación aunque de manera limitada, todo esto en virtud de la regulación laboral.

Por otro lado, el ámbito deontológico o de la responsabilidad profesional dota al abogado-trabajador de una serie de derechos y obligaciones para el ejercicio profesional, los cuales deben mantenerse en el ejercicio subordinado de la abogacía.

Entre los deberes y derechos que la profesión instaura al abogado, tenemos el secreto profesional, libertad para aceptar y renunciar a un encargo, patrocinio debido, guardar el decoro, apariencia debida, deber de diligencia, evitar conflictos de intereses, responsabilidad social, entre otros. En la práctica, hemos verificado que el ejercicio de la carga deontológica del profesional en Derecho pugna con los intereses de su empleador, lo cual hace un frente al poder de dirección que este pretende ejercer válidamente sobre aquel.

Ahora bien, aquí encontramos posibles problemas en el plano deontológico del abogado-trabajador, ya que, si bien el empleador puede variar la prestación dentro de la categoría (servicios legales), nos preguntamos qué sucedería si el nuevo encargo afecta la conciencia del abogado-trabajador o si lo involucra en un conflicto de intereses, ya sea de manera potencial

9 Algunos autores clasifican los límites del poder de dirección estableciendoa los derechos fundamentales como límites externos o extrínsecos. Véase Blancas Bustamante, Carlos. Op. cit., p. 109.

10 ValdésDalRémencionaquelos derechosfundamentalesson «límites infranqueablesqueelempresariono les debedesconoceren uso desu poder dedirección». Véase VALDÉs DAL RÉ. «Los derechosfundamentales de la persona del trabajador». En Libro de Informes Generales del XVII Congreso Mundial de Derecho de Trabajo y de Seguridad Social. Montevideo: Asociación Uruguaya de Derecho del Trabajo y de la Seguridad Social, 2003, p. 99.

11 Toyama Miyagusuku, Jorge. «Los derechos fundamentales de los trabajadores en la empresa». Análisis de la Sentencia № 3935-99-I.D. (S). Diálogo con la jurisprudencia. Actualidad, análisis y crítica jurisprudencial. Lima: Gaceta Jurídica, 2000, pp. 67-77.

EL EJERCICIO SUBORDINADO

DE LA ABOGACÍA:

LIIMITES E IMPLI-

CANCIAS DE LAS CARGAS DEONTO-

LÓGICAS SOBRE

LA RELACIÓN

LABORAL DEL

ABOGADO 
o actual. ¿Podría el abogado ampararse en su libertad de aceptar el encargo $^{12}$ para decidir frente a la orden del empleador acerca de tomar o rechazar el pedido? ¿El Derecho laboral le brinda alguna herramienta al abogado-trabajador para no cumplir con el encargo encomendado? ¿Es válido que el abogado-trabajador pierda su trabajo por negarse a acatar una orden — que en principio es legítima— de su empleador?

En este escenario, la convivencia de las disposiciones labores y deontológicas no es pacífica, con lo cual una primera conclusión sería considerar que estos califican como un límite adicional al poder de dirección del empleador.

\section{BUSCANDO SOLUCIONES: EL DERECHO DE RESISTENCIA O JUS RESISTENTIAE}

Como ya hemos adelantado a lo largo de la investigación, las órdenes empresariales no pueden ser lesivas a los derechos del trabajador y a la vez se presume iuris tantum la legitimidad de dichas órdenes, por lo cual se deriva el deber del trabajador de obedecerlas.

Sin embargo, el Derecho laboral otorga a los trabajadores el llamado «derecho de resistencia», que en buena cuenta es un no acatamiento del acto patronal en ciertas circunstancias justificadas. Al respecto, Ermida Uriarte señala que:

[...] el trabajador, en teoría, tiene la resistencia directa, el no acatamiento. Decimos que esta defensa existe en «teoría» por dos motivos: en primer lugar, porque en muchos casos el trabajador se verá impedido de hecho de ejercer tal resistencia, dada su situación de subordinación jurídica -y generalmente también fáctica-; y en segundo lugar, porque en muchos casos la simple desobediencia no será posible, como por ejemplo, en aquellas situaciones en que la alteración se consuma con la sola voluntad y acción del patrono. Pero allí donde la alteración requiera para consumarse alguna algún hacer del trabajador afectado, la resistencia de éste sería jurídicamente posible. ${ }^{13}$

Por su parte, Montoya Melgar ${ }^{14}$ agrega que «[...] El trabajador, pues, está legitimado para desobedecer las órdenes que no supongan "ejercicio regular" de las funciones de mando del empresario [...]».

Dicho esto, ante órdenes ilegítimas, el trabajador cuenta con la herramienta del derecho de resistencia para oponerse a dicha directriz y justificar su no cumplimiento.

12 Lalibertadparaaceptarunencargoes underechodelabogadoreconocidoenelCódigodeÉticadelColegio de Abogados de Lima.

13 ERmidA, Óscar. Modificación de las condiciones de trabajo por el empleador. Buenos Aires: Editorial Hammurabi, 1989, pp. 95-96.

14 Montoya Melgar, Alfredo. Derecho del trabajo. Décimo primera edición. Madrid: Editorial Tecnos S.A, 1990, p. 313. 
Ahora bien, en nuestra opinión, la emisión de una orden ilegítima por parte del empleador no es el único supuesto para activar el derecho de resistencia para el caso del abogado-trabajador que hemos venido analizando, ya que, en el caso específico, este también se activaría ante cualquier orden que contravenga la carga deontológica que posee el abogado-trabajador. Es decir, pueden existir órdenes completamente legítimas que no implican una rebaja de categoría ni cambio de ubicación geográfica, ni que tampoco representan afectación alguna a los derechos fundamentales del abogado-trabajador, y, sin embargo, constituyen vulneraciones directas a los derechos y deberes deontológicos que todo abogado tiene por ser tal —y que, en todo caso, anteceden a las obligaciones laborales que vienen determinadas por el contrato de trabajo-

Ya en el punto III habíamos esbozado una lista de algunos deberes y derechos que la profesión implanta al abogado, todos ellos establecidos en el Código de Ética del Colegio de Abogados del Perú. A continuación, pasaremos a analizar algunos de ellos para indagar cómo estos dotan de contenido al derecho de resistencia y cuáles son los posibles conflictos a presentarse en la interacción con las disposiciones laborales:

\section{Secreto profesional}

Según Schimdt, ${ }^{15}$ por definición, un «secreto profesional es información confidencial recibida por una persona en el ejercicio de su profesión»; en este sentido, «cualquier persona tiene la obligación moral de usar este tipo de información solo para los fines para los cuales le haya sido confiada» y, por tanto, «falta a su deber profesional si la revela a personas no autorizadas o si la usa en provecho personal».

A esta definición se ajusta el Proyecto de Código de Responsabilidad Profesional del Abogado, ${ }^{16}$ cuando en el artículo 26 se menciona que «El secreto profesional es el deber de reserva que se impone al abogado para proteger y mantener en la más estricta confidencialidad, hechos e información de un cliente o de un potencial cliente que conoce por cualquier medio con ocasión de la relación profesional».

Podemos deducir entonces que el secreto profesional es una de las más importantes obligaciones que se genera cuando un abogado establece una relación con su cliente o llega a adquirir información de un potencial cliente. Como podemos advertir, esta obligación ${ }^{17}$ se activa ante el

15 Schmidt, Eduardo. Ética y negocios para América Latina. Lima: Universidad del Pacífico, 2001, pp. 205-206. 16 LatareadereformarelCódigodeÉticadelos AbogadosvigenteesunproyectolideradoporJorge Avendaño Valdez, bajolasecretaríadeBeatrizBoza.Laredaccióndelcapítulo «Secretoprofesional» estuvoacargode AlfonsodelosHeros, CésarLuna Victoria,JulioSalas, Andrés Valle,JuanLuis Hernández, AntonioGuarniz, Marielena Houghton y Christian Chocano.

17 Endoctrina,elsecretoprofesionalnosoloesconsideradocomoundeber,sinotambiénesseñaladocomoun derechodelabogado,yaque,enalgunossupuestos, nobastalaautorizacióndelclienteparaqueelabogado revelelainformaciónconfiada.Asimismo,elabogadopuedeoponerestederechoantelasautoridadesoante cualquier tercero que pretendaobtenerlainformación-porejemplo,elabogadopuedenegarseadeclarar como testigo en un proceso o asistir y simplemente guardar silencio durante el interrogatorio-.

EL EJERCICIO SUBORDINADO DE LA ABOGACÍA: LÍMITES E IMPLICANCIAS DE LAS CARGAS DEONTOLÓGICAS SOBRE LA RELACIÓN LABORAL DEL ABOGADO 
cliente - $\mathrm{O}$ ante uno potencial-, con lo cual debemos estar atentos para reconocer quién es el cliente del abogado-trabajador.

Una primera aproximación sería descartar el hecho de identificar a quien paga los honorarios con el cliente porque esto no siempre ocurre, ya que los honorarios pueden ser cubiertos por un tercero, ajeno a la relación profesional, frente al cual el abogado-trabajador no podría revelar información alguna, por más que sea él quien asuma la factura por servicios legales.

Sobre esta línea, hemos mencionado que, en principio, los honorarios no son equivalentes a la remuneración propiamente dicha y que un abogado-trabajador recibirá una remuneración como contraprestación por los servicios brindados en el marco de un contrato de trabajo, con lo cual quedaría descartada la idea de considerar al empleador como el «cliente». Por tanto, más allá de las obligaciones laborales del abogado-trabajador que se circunscriben básicamente al desarrollo de la prestación en los términos del contrato de trabajo, somos de la opinión de que el abogado-trabajador no está obligado a revelar a su empleador información confidencial obtenida en el contexto de la relación profesional con su cliente, cuyos intereses protege a raíz de asumir el encargo.

Para graficar el asunto, consideramos que el dilema más drástico en el caso de la obligación de confidencialidad se presenta cuando, por ejemplo, abogados de una misma firma ${ }^{18}$ asesoran a ambas partes de una operación financiera al dividirse en equipos y basarse en las llamadas Chinese walls. ${ }^{19}$ En este caso, el abogado-trabajador no deberá revelar información alguna a su empleador, ni mucho menos a terceros que se lo soliciten, por las razones señaladas líneas arriba. Por tanto, si su empleador requiere un informe detallado sobre el estatus de la operación, este podrá negarse a cumplir dicha orden, que en principio es válida, al ampararse en el secreto profesional. Distinto es el caso en el cual el empleador, en su facultad de monitorear los trabajos que ha delegado, solicite estatus del encargo, claro está, si es que no existe una chinese wall de por medio.

Otro caso límite es el abogado-trabajador del Ministerio de Transportes y Comunicaciones quien ha recibido el encargo de defender en un proceso judicial a un ex ministro. ${ }^{20}$ En este caso, si el empleador - el ministerio - requiere información sobre la gestión de su ex ministro, medida en términos de culpabilidad o inocencia, el abogado-trabajador deberá negarse a revelar información sobre el tema, toda vez que el abogado se debe a su cliente, el cual en este caso recaería sobre el

18 Utilizaremos los términos «firma» o «estudio» para referirnos a un estudio de abogados.

19 Las Chinese walls ('murallas chinas') son una práctica generalizada en el mundo de los abogados, que consiste en formar equipos completamente independientes para asesorar a ambas partes - y al mismo tiempo-en un conflicto. En mi opinión, esta figura es una creación de los abogados para lucrar más, ya quealutilizarlaspuedenobtenermayoresbeneficioseconómicosaltenerunclientemásparaasesorarlo,sin importar que dicho cliente esté directamente en conflicto con otro cliente suyo.

20 Soloporponerunejemplo, partiendodelapremisadequesetratadeunabogadoquecuentaconuncontrato de trabajo con la citada organización. 
ex ministro, ya que es a él a quien defiende, y no sobre el sujeto que le otorga una remuneración.

En estos casos, somos de la opinión de que el empleador no podría imputarle al abogado-trabajador falta grave alguna por incumplimiento de sus obligaciones laborales, toda vez que este se ha amparado en todo momento en los deberes deontológicos que rigen el ejercicio de la profesión. A pesar de ello, retomaremos el debate más adelante.

\section{Libertad para aceptar un encargo}

Esta es una de las facultades más importantes de las que goza el abogado y que implica la potestad de negarse a aceptar un asunto. Este derecho del abogado pareciera verse disminuido cuando se encuentra en el marco de una relación laboral, toda vez que negarse a asumir un encargo equivaldría a negarse a cumplir una orden, otra vez válida, de su empleador.

La facultad para decidir sobre aceptar un encargo ha sido recogida en el artículo 14 del Proyecto de Código de Responsabilidad Profesional del Abogado, ${ }^{21}$ en el que se señala lo siguiente:

El abogado debe examinar con seriedad y sumo cuidado los asuntos que se le proponen antes de decidir aceptarlos. Tiene el derecho de aceptar o rechazar un patrocinio, sin tener que justificar su decisión. En el supuesto [de] que el abogado esté inmerso en una relación de dependencia, podrá rechazar un patrocinio justificando debidamente su decisión [...]». (la cursiva es nuestra).

En este escenario, para que el abogado-trabajador asuma un encargo, deberá realizar el siguiente test: ${ }^{22}$

i. Informarse bien, lo cual implica conocer quién es el cliente y obtener al detalle todos los hechos e implicancias de las conductas involucradas en el asunto.

ii. Analizar si existen conflictos de interés, ya sean actuales o potenciales, es decir, evaluar si el interés por el que el abogado-trabajador vela no se enfrenta con cualquier otro interés que pudiese influir en el desarrollo del caso por parte del abogado-trabajador —incluido el propio interés del abogado-, pasando, además, por un tema de lealtad e independencia.

iii. Competencia, lo cual incluye realizar un análisis a fin de verificar que el abogado-trabajador cuente con las aptitudes idóneas para asumir el encargo.

iv. Validez del encargo, si es lícito y/o moral.

EL EJERCICIO SUBORDINADO

DE LA ABOGACÍA:

LIIMITES E IMPLI-

CANCIAS DE LAS

CARGAS DEONTO-

LÓGICAS SOBRE

LA RELACIÓN

LABORAL DEL

ABOGADO 
v. Informar al cliente de su situación, sin prometer resultados exitosos.

Solo luego de esta evaluación el abogado-trabajador estará en una mejor situación para decidir si asume el encargo o no.

\section{Libertad para renunciar a un encargo}

Es la facultad que tiene el abogado para dar término a la relación profesional por su sola decisión, siempre que se presente una causal justificada sobreviviente, lo cual impide la resolución de la relación laboral por el libre antojo del abogado.

Al respecto, el Proyecto de Código de Responsabilidad Profesional del Abogado ${ }^{23}$ recoge el tema principalmente en el artículo 17, donde señala que «El patrocinio concluye por acuerdo entre el abogado y el cliente o por renuncia del abogado, siempre que exista causa justificada sobreviniente [sic] y cuidando que no se perjudiquen sustancialmente los intereses del cliente».

Como podemos observar, queda en duda si el abogado-trabajador mantiene la facultad tal cual ha sido descrita o si, a raíz del contrato de trabajo, esta se encuentra limitada o inclusive anulada.

En nuestra opinión, el abogado-trabajador podrá renunciar al encargo ante su empleador al exponerle los motivos justificados de su decisión. El empleador deberá realizar un análisis de las circunstancias y autorizarle al abogado-trabajador la renuncia del patrocinio, lo cual se comunicará inmediatamente al cliente, quien deberá recibir garantías de que no queda desprotegido y quien guardará discreción respecto de lo que se le ha informado.

Así, una conclusión preliminar sería que el contrato de trabajo hace que las cargas deontológicas no siempre se desarrollen automáticamente, sino que deban ser consultadas antes con el empleador a fin de comunicar el límite que presenta el abogado-trabajador para continuar con el desarrollo de la prestación. Como ya hemos mencionado, es innegable que un abogado sujeto a una relación laboral está subordinado al poder de dirección del empleador, el cual, creemos, no anula la carga deontológica del trabajador, pero sí la limita.

\section{Deber de evitar conflictos de intereses}

Al definir el conflicto de intereses, Hans Kelsen señala que:

El conflicto de intereses aparece cuando un interés encuentra su satisfacción sólo a costa de otro o, lo que es lo mismo, cuando entran en oposición dos valores y no es posible hacer efectivos ambos, o cuando 
el uno puede ser realizado únicamente en la medida en que el otro es pospuesto, o cuando es inevitable el tener que preferir la realización del uno a la del otro y decidir cuál de ambos valores es el más importante y, por último, establecer cuál es el valor supremo. ${ }^{24}$

Debido a la interacción del abogado, más aun del abogado miembro de un estudio - inclusive bajo una relación laboral—, es muy fácil generar conflictos de intereses. Los más comunes son los conflictos por interés de un familiar, por interés propio, por un actual cliente o por uno meramente potencial.

En este escenario, desde la perspectiva del Derecho laboral, es usual que el empleador emita una orden que afecte la independencia del abogadotrabajador y que lo obligue a generar un conflicto de interés. Es decir, el empleador, en ejercicio legítimo de su poder de dirección, puede ordenar al abogado-trabajador la ejecución de actividades incluidas en la prestación pactada y generar, indirectamente, un abierto y frontal conflicto de intereses para el abogado-trabajador.

Frente a ello, somos de la opinión de que el abogado-trabajador deberá informar inmediatamente acerca del conflicto, inclusive si aún es potencial, y ampararse en su deber de evitar estas situaciones para activar el derecho de resistencia e incumplir válidamente la orden del empleador.

Hasta aquí hemos descrito las principales obligaciones deontológicas del abogado, las cuales no siempre se trasladan a la relación laboral de manera pacífica. Ahora bien, icuál es el contenido de la potestad del abogado-trabajador para negarse a cumplir una orden de su empleador?

Consideramos que la respuesta dependerá de cada caso. Sin embargo, la premisa estándar de todo abogado que desarrolle sus servicios de manera subordinada bajo una relación laboral deberá ser privilegiar las cargas deontológicas que posee sobre las obligaciones laborales nacidas con posterioridad al contrato de trabajo.

A continuación, presentaremos casos extremos para graficar nuestras conclusiones:

i. En el lapso de un mes, el abogado-trabajador se ha negado ya diez veces a asumir diversos encargos, para lo cual ha alegado diversas razones en virtud de su libertad para aceptar o rechazar un encargo. ¿Puede el empleador despedirlo válidamente?

Ante ello, podríamos alegar, en favor del empleador, que él contrató a un abogado con la finalidad de que brinde servicios legales; es decir, incorporó a su organización a un abogado capacitado para desarrollar la prestación pactada en el contrato de trabajo y que, al encontrarse el abogado impedido de desarrollar el encargo

EL EJERCICIO

SUBORDINADO

DE LA ABOGACÍA:

LÍMITES E IMPLI-

CANCIAS DE LAS

CARGAS DEONTO-

LÓGICAS SOBRE

LA RELACIÓN

LABORAL DEL

ABOGADO 
por sus «motivos deontológicos», ya no le era de utilidad para cumplir con la finalidad. Por tanto, podría resolver válidamente el vínculo laboral al alegar incapacidad del trabajador para cumplir con el contrato de trabajo.

Sin embargo, no estamos de acuerdo con el análisis señalado. En nuestra opinión, el empleador deberá respetar las cargas deontológicas del abogado-trabajador y respetar su negativa justificada para cumplir con las órdenes, por haberse amparado en el derecho de resistencia. Es más, escapando un poco del Derecho laboral, si un abogado se niega a acatar una orden al alegar conflicto de intereses, esto puede ser hasta provechoso para el empleador cuya organización compite en un mercado de servicios legales, puesto que la imagen de transparencia y preocupación por evitar conflictos de intereses en una corporación es bastante valorada en el mercado. Ello puede incidir en cómo lo perciben los demás competidores - e incluso los clientes- en el desarrollo de la profesión.

ii. Ahora bien, digamos que el abogado-trabajador no ha celebrado pactos de exclusividad y no competencia con su empleador y que, en sus horas libres, luego de cumplir con su jornada de trabajo, atiende algunos clientes en su pequeño despacho que maneja de manera independiente. Un buen día, el empleador le solicita que se haga cargo de un asunto que el abogado-trabajador se niega a atender, toda vez que él patrocina, de manera independiente, a la contraparte involucrada en dicho asunto.

Ante este claro conflicto de intereses, el empleador admite que no puede obligarlo a tomar el encargo. En este supuesto, nos preguntamos si el empleador puede obligar al abogado-trabajador a renunciar al encargo ya asumido, por un tema, tal vez, de buena fe.

Aquí se presentan dos temas. El primero supone preguntarnos si hace falta establecer pactos de exclusividad y no competencia entre el empleador y el abogado-trabajador, a pesar de que la relación laboral se basa en la premisa de la buena fe, con lo cual el trabajador estaría obligado a no realizar acto alguno que fuera en contra de los intereses de su empleador. Sobre ello, tomando en cuenta las calificaciones especiales del trabajador, se amerita la celebración de estos pactos cuando el empleador lo considere pertinente. Sin embargo, esto no es una regla general, ya que sobre los pactos de exclusividad, como Sergio Quiñones ${ }^{25}$ ha señalado, «[...] el pluriempleo — como manifestación de la libertad constitucional de trabajo - debe ser la regla general, mientras que los pactos de exclusividad o plena dedicación constituyen la excepción $[\ldots]$ ». 
De lo anterior se desprende que el abogado-trabajador puede atender válidamente a otros clientes fuera de su horario de trabajo y aun así actuar dentro de los márgenes de la buena fe. ${ }^{26}$

Sobre el mismo caso, un tema adicional supone analizar si se admite que el empleador obligue al trabajador a renunciar al encargo ya asumido al alegar que, en virtud de la buena fe, el abogado-trabajador debe ser precavido y no andar «sembrando» conflictos de intereses que luego repercutirán en su relación laboral.

Creemos que el tema es discutible. No obstante, una primera aproximación nos llevaría a concluir que el empleador tiene a mano todas las herramientas necesarias para protegerse; es decir, se encuentra en una posición de ventaja ante el trabajador - a pesar de que este sea un abogado-. Por tanto, si aun así no crea mecanismos adecuados para evitar la generación de situaciones que impidan el desarrollo de la prestación por parte de sus trabajadores, entonces debería asumir los costos de ello.

Hasta aquí hemos analizado diversas situaciones en las cuales se enfrenta claramente el poder de dirección del empleador con los deberes y derechos deontológicos del abogado-trabajador. Una salida propuesta es ampararse en el derecho de resistencia que la legislación laboral otorga a los trabajadores para incumplir válidamente las órdenes del empleador bajo el amparo del poder de dirección.

En conclusión, nuestra propuesta es que los deberes y derechos deontológicos del abogado permiten activar el derecho de resistencia para incumplir órdenes en la dinámica de la relación laboral. Asimismo, la carga deontológica calza perfectamente como un tercer límite del poder de dirección del empleador.

\section{CONCLUSIONES}

De acuerdo con la línea de razonamiento que hemos planteado a lo largo del presente trabajo, consideramos que es posible llegar $-\mathrm{y}$ reafirmar-a las siguientes conclusiones:

1. Si el abogado cumple con los tres requisitos de un contrato de trabajo, el desarrollo de sus servicios se encuadrará, necesariamente, dentro de una relación laboral.

2. Los ámbitos de la ética, la moral, la responsabilidad profesional y, en general, la deontología no son ajenos al contrato de trabajo.

EL EJERCICIO SUBORDINADO

DE LA ABOGACÍA:

LÍMITES E IMPLI-

CANCIAS DE LAS

CARGAS DEONTO-

LÓGICAS SOBRE

LA RELACIÓN

LABORAL DEL

ABOGADO 
3. El empleador tiene las atribuciones de dirigir, fiscalizar y sancionar al abogado-trabajador, lo que en doctrina es llamado «poder de dirección».

4. Respecto del trabajador, el poder de dirección surge como una consecuencia inmediata, en favor del empleador, de la suscripción del contrato de trabajo entre trabajador y empleador. Por tanto, el empleador es el titular del poder de dirección y sus directrices están dotadas de una presunción de legitimidad.

5. La convivencia de las disposiciones labores y deontológicas no es pacífica, con lo cual una primera conclusión sería considerar que estos califican el poder de dirección del empleador como un límite adicional.

6. Ante la negativa de cumplir las órdenes del empleador, este no podrá imputarle al abogado-trabajador falta grave alguna por incumplimiento de sus obligaciones laborales, toda vez que se ha amparado en todo momento en los deberes deontológicos que rigen el ejercicio de la profesión.

7. La libertad para aceptar un encargo no se anula bajo el régimen laboral; sin embargo, sí queda limitada.

8. El abogado-trabajador podrá renunciar al encargo de su empleador al exponerle los motivos justificados de su decisión, ante lo cual el empleador deberá realizar un análisis de las circunstancias y autorizarle al abogado-trabajador la renuncia del patrocinio.

9. El abogado-trabajador deberá informar inmediatamente a su empleador sobre un conflicto de intereses, inclusive si es potencial, y ampararse en su deber de evitar estas situaciones para activar el derecho de resistencia e incumplir válidamente la orden del empleador.

10. El empleador deberá respetar las cargas deontológicas del abogado-trabajador y respetar su negativa justificada para cumplir con las órdenes, al ampararse en el derecho de resistencia.

11. El abogado-trabajador puede atender válidamente a otros clientes fuera de su horario de trabajo y aun así actuar dentro de los márgenes de la buena fe.

12. El empleador tiene a mano todas las herramientas necesarias para protegerse. Por tanto, si aun así no crea mecanismos adecuados para evitar la generación de situaciones que impidan el desarrollo de la prestación por parte de sus trabajadores, debe asumir los costos de ello.

Los deberes y derechos deontológicos del abogado permiten activar el derecho de resistencia para incumplir órdenes en la dinámica de la relación laboral. 